\title{
Universal Basic Income and the Economy Effect
}

\author{
Jeremy Wolf ${ }^{1}$
}

This paper examines some of the ways in which proposals for "universal basic income" may have potential for conceptual innovation with respect to the object to which we refer as "the economy." Employing the work of Gibson-Graham and Mitchell, the paper suggests that we might think about practices related to the economy as acts of signification through which we produce and maintain the appearance of a difference between those aspects of human existence that are treated as part of the economy and those that are not. The paper then suggests that proposals for universal basic income have the potential to lead to conceptual innovation with respect to the ways in which we construct this line of distinction between the economy and the extra-economic. [Article copies available for a fee from The Transformative Studies Institute. E-mail address: journal@transformativestudies.org Website: http://www.transformativestudies.org (O2020 by The Transformative Studies Institute. All rights reserved.]

KEYWORDS: Structural Effect, Economy, Universal Basic Income.

While it is certainly not a new idea, in recent years calls for a Universal Basic Income (UBI), also sometimes referred to as an unconditional or basic income, have become more common and, to many, more compelling. There is a sense of facial validity to the claim that increasing automation (along with concentration of capital) is likely to make full employment impossible without the intentional creation of busywork (e.g. Berger, 2017; Clifford, 2018; and Darrow, 2017). Why, ask supporters of the UBI, should we find ways to make work instead of decoupling access to life's necessities from work? That is, if there is not enough work to go around, but we're still making plenty of stuff, maybe the problem lies in the idea that we have to work to get stuff (Chamberlain, 2018).

UBI is a particularly interesting proposal because, in addition to having far-reaching potential to alter the ways in which we relate to

\footnotetext{
${ }^{1}$ Jeremy Wolf, PhD., is an Assistant Professor of Political Science at SUNY Cortland. His work focuses on political theory and American politics.
} 